\title{
School-based human papillomavirus vaccination: An opportunity to increase knowledge about cervical cancer and improve uptake of screening
}

\author{
G Dreyer, ${ }^{1} \mathrm{MB} \mathrm{ChB}$, MMed (O\&G), MCOG (SA), PhD; F H van der Merwe, ${ }^{2} \mathrm{MB}$ ChB, $\mathrm{MMed}(\mathrm{O} \& \mathrm{G}), \mathrm{FCOG}$; \\ M H Botha, ${ }^{2}$ MB ChB, MMed (O\&G), FCOG (SA), PhD; L C Snyman, ${ }^{1}$ MB ChB, MPraxMed, MMed (O\&G), FCOG (SA); \\ D Constant, ${ }^{3} \mathrm{MSc}, \mathrm{MPH}$; C Visser, ${ }^{1} \mathrm{BSc}$ Hons, MSc; J Harvey, ${ }^{4} \mathrm{MCom}, \mathrm{PhD}$ \\ ${ }^{1}$ Department of Obstetrics and Gynaecology and Gynaecological Oncology Unit, Faculty of Health Sciences, University of Pretoria, South Africa \\ ${ }^{2}$ Department of Obstetrics and Gynaecology and Unit for Gynaecological Oncology, Faculty of Medicine and Health Sciences, Stellenbosch \\ University, Tygerberg, Cape Town, South Africa \\ ${ }^{3}$ Women's Health Research Unit, School of Public Health, Faculty of Health Sciences, University of Cape Town, South Africa \\ ${ }^{4}$ Centre for Statistical Consultation, Stellenbosch University, Western Cape, South Africa
}

Corresponding author: G Dreyer (gretadreyer@mweb.co.za)

\begin{abstract}
Background. Poor knowledge about cervical cancer plays a role in limiting screening uptake. HPV vaccination provides an untested platform to distribute information that could possibly improve knowledge and screening coverage.

Objective. To measure changes in knowledge and screening uptake when information and screening opportunities were provided to mothers of adolescent HPV vaccine recipients.

Methods. During an HPV vaccine implementation project in the Western Cape (WC) and Gauteng Province (GP), South Africa, information about cervical cancer was provided to parents during a lecture, written information was distributed, and mothers were then invited to either screen at their clinic (WC) or use a self-screening kit (GP). A structured questionnaire was used to test cervical cancer knowledge and screening practices, comparing these before and after the project and between the two screening groups.

Results. Complete data for both questionnaires were available for 777 of 906 recruited women. Initial knowledge was poor, but on retesting 6 months later, knowledge about symptoms $(p<0.005)$, screening $(p<0.005)$ and vaccination $(p<0.05)$ improved significantly after the information session and school-based HPV vaccination. In the second questionnaire, women reported significantly more screening and the last reported screening test was more recent. This improvement was more favourable in GP than in the WC (41\% v. $26 \%$ reporting screening in the past 12 months).

Conclusion. These results demonstrate how adolescent HPV vaccine programmes can help to control cervical cancer among mothers by offering information and screening. It is important not to lose this opportunity to educate mothers and their daughters and offer effective methods to prevent cervical cancer in both generations.
\end{abstract}

S Afr Med J 2015;105(11):912-916. DOI:10.7196/SAMJ.2015.v105i11.9814

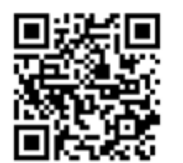

Cervical cancer in South Africa (SA), as in most developing countries, remains an unchecked epidemic $^{[1-3]}$ Although reasons for the high prevalence and late presentation are complex, poor uptake of screening plays a major role. Together with health systems factors, educational level and knowledge determine healthseeking behaviour and therefore screening coverage. Many authors have investigated knowledge about cervical cancer among SA women, and have generally reported this to be lacking. ${ }^{[4-7]}$

It is expected that improved knowledge of cervical cancer will translate into an improvement in screening uptake. If knowledge can be improved by verbal or written communication, parents of human papillomavirus (HPV) vaccine recipients would be an appropriate target for such an educational drive. These mothers are not realistic targets for primary prevention, but should be in the appropriate age group for screening. In addition, information about the two modalities of prevention seems to combine well.

Linking various health interventions to school-based HPV vaccination is a popular idea because preadolescents generally do not present for health information or care. ${ }^{[8-10]}$ Potential disadvantages include a diluted message, increased cost and the possibility that connecting this vaccine to sexual health may decrease uptake. It is therefore essential that any planned health intervention be evaluated and motivated thoroughly before implementation.

The main aim of this project was to investigate whether an educational drive to improve knowledge and screening of mothers can be successful when linked to school-based HPV vaccination. In order to answer this question, knowledge and screening behaviour were tested before and after an educational intervention, followed by an invitation to participate in screening.

\section{Methods}

The Vaccine and Cervical Cancer Screen (VACCS) project aimed to vaccinate 2000 primary schoolgirls in Gauteng Province (GP) and the Western Cape (WC) during 2011 and 2012, after approval from the national and provincial departments of health and basic education. The study was also approved by the institutional research ethics review committees of the universities of Pretoria (219/2009) and Stellenbosch (N11/01/008). Schools were selected on the basis of geographical distribution and consent from headmasters and school governing bodies. Printed information, consent and invitation material was distributed to all girls in grades $4-7$. These pamphlets invited parents to consent to vaccination of their daughters and to attend information events at schools where they would receive more detailed information. 
After receiving information about the project, parents and female guardians were invited to participate in a questionnaire study and had to provide written consent. The questionnaire (Q1) contained both open-ended and closed questions on demographics and aspects of cervical cancer and its prevention, and was administered by medical students who asked the questions and recorded answers. The educational intervention followed, consisting of a 15-minute PowerPoint presentation by a medical doctor and information leaflets covering most of the information assessed in the questionnaire. Parents and daughters were invited to sign consent and assent for the girl child to be vaccinated, and all mothers were invited to partake in cervical cancer screening.

Two different types of screening were employed in the two study sites to evaluate and compare impact on screening behaviour. In the WC, where cervical screening services are better developed, mothers were encouraged to visit their nearest clinic and undergo conventional cytology-based screening. In GP, female parents and guardians were offered a tampon collection kit for HPV determination with written information on how to self-collect the sample. These specimens were collected from the school during the following month and tested for high-risk HPV, and women who screened positive received results and an invitation to further investigation and treatment if necessary ${ }^{[11]}$ All women received results via cell phone messaging (texting).

During the following months, vaccination took place at the school and telephonic interviews were conducted with the mothers after 6 months, repeating the same questions (Q2). Data from the two questionnaires were analysed to determine levels of knowledge and self-reported screening behaviour before and after the study. Differences between the answers were determined for each participant and analysed. Outcomes of the vaccination programme and the main results of the self-screening study have been reported elsewhere. ${ }^{[12]}$

\section{Data management}

Questionnaire data consisted of basic demographic data, information about access to and use of healthcare facilities, knowledge of cervical cancer and previous cervical cancer screening. Questions were asked to test basic knowledge about cervical cancer and protection against the disease, followed by questions on previous cervical cancer screening tests and their results. Using these data, knowledge scores were calculated by awarding points for correct answers to a maximum score of 5 marks each for knowledge about cervical cancer symptoms, screening options and vaccination (the scoring system is shown in Appendix 1, available in the online version of this article). For each of these three, a critical minimum score was determined based on information supplied at the lecture. It was then calculated in terms of how many women's knowledge improved to this critical minimum between the first and second questionnaires.

Because two different methods were employed to impact on screening behaviour at the two study sites, data on changes in screening uptake were analysed separately for these two groups. For screening behaviour, a score was calculated (behaviour score) according to the time of the last reported screening test. After completing the questionnaire at the start and end of the study, all participants who improved their 'time of last screening test' to $<1$ year ago were considered study screen participants.

\section{Results}

\section{Demographic data}

We invited all attending parents to participate in the study, of whom only two were excluded (male parents were ineligible). Questionnaire data were available for 906 women, and 777 also completed the second questionnaire. Loss to follow-up was due to inability to make telephonic contact or refusal to answer Q2. Demographics of this group were not different to the total group. The median age of the participants was 38.0 years and the level of education varied between very little formal schooling (up to grade 7 in $10.1 \%$ of women) and tertiary education (23.3\% of women). Half of all participants received a salary and another $6.8 \%$ were self-employed. Differences between the provinces were significant, with parents at the GP schools being slightly younger and better educated. ${ }^{[13]}$

\section{Knowledge about cervical cancer and its symptoms before and after health education}

Before the educational intervention, knowledge about cervical cancer and its symptoms was similarly poor among participants in both sites, with $31.7 \%$ of the total group ( $n=906$ ) saying that they knew nothing about cervical cancer or did not know what it was. Among those who answered questions about the symptoms of cervical cancer, pain was mentioned most commonly as an important symptom (30.0\%), followed by discharge (20.9\%). Significantly more women in the WC cohort than in GP knew that unusual bleeding was a symptom $(24.0 \%$ v. $18.3 \%$; $p=0.04)$. In the second interview, only $11.9 \%$ of respondents said that they knew nothing about cervical cancer. Knowledge about the important symptoms of the disease improved, and $46.8 \%$ respondents mentioned pain, $42.1 \%$ unusual bleeding and $32.0 \%$ discharge. These answers are shown in Appendices 2 and 3 (available in the online version of this article).

\section{Knowledge about cervical cancer prevention before and after health education}

With regard to cervical cancer prevention, $53.1 \%$ of respondents initially said that they knew how a woman can protect herself against the disease; $86.1 \%$ of these women $(24.6 \%$ of the total) mentioned a Pap smear as protective. Other answers included some form of medical care, protective sexual practices such as condoms, vaccines, or not having sex (only 2.4\%).

After the health education intervention, $83.3 \%$ of respondents thought that they knew how to protect against cervical cancer. In the total group, $66.5 \%$ now mentioned 'Pap smear' as protective. The biggest change was seen in knowledge that the vaccine exists, which increased from $4.2 \%$ to $26.3 \%$. These data were also elicited by an open-ended question, and some answers are shown in Appendix 4 (available in the online version of this article).

When asked whether they had ever heard of a vaccine against cervical cancer, $17.2 \%$ answered 'yes' before the project, and $84.1 \%$ at the end of the project. Only $15.9 \%$ of participants attempted to answer the question on preferred recipients of HPV vaccines, mostly correctly. However, attitude towards and trust in vaccines were very positive, with $90.6 \%$ of respondents saying that the vaccine will be good to have, and $89.8 \%$ saying that they would advise primary schoolgirls to have it. Responses to these last two questions at the end of the study were even better (97.4\% and $98.1 \%)$.

\section{Knowledge scores and changes after intervention}

Using the method described above, knowledge scores were calculated both before and after the information event and compared per participant for those women who completed both questionnaires. Data for the complete group are set out in Table 1, showing a trend of improvement in knowledge scores (graphically illustrated in Diagrams 1 - 3, available in the online version of this article).

According to the critical or essential level of knowledge, participants were divided into three groups: those whose knowledge scores improved to adequate levels, those who remained at the same level of adequacy, and those who demonstrated poorer knowledge at the second interview. 
Initially, 30.8\% of participants (239/777) attained a knowledge score of $0 / 5$ for cervical cancer and its symptoms, considered to be inadequate, while only $9.1 \%$ remained at a knowledge score of 0 after attending the health education event. In $21.6 \%$ of women knowledge scores improved to a level of adequacy. The improvement was statistically significant $(p<0.005)$ and the data are shown in Table $2(\mathrm{~A})$.

Similarly, for cervical cancer screening any knowledge score above $0 / 5$ was considered adequate for the purposes of this analysis. After education, $62.9 \%$ had confirmed adequate knowledge, v. $30.6 \%$ before. Improvement per person was also statistically significant $(p<0.005)$ (Table 2, B).

Scoring for vaccine knowledge included two questions that actually tested attitude towards vaccines, requiring a 'yes' or 'no' answer. In view of the positive attitudes towards vaccines in general, vaccine knowledge scores were generally good. A minimum score of $3 / 5$ was considered adequate and was attained by $17.6 \%$ at the start of the study and $80.8 \%$ at the end of this study $(p=0.045)$ (Table $2, C)$.

\section{Screening behaviour scores and changes after the intervention}

Women were asked whether they ever had a cervical cancer test and how long ago the last test had been. Answers were used to calculate a screening behaviour score, and scores of $0 / 5$ were awarded for 'never' or 'unsure if ever', $1 / 5$ for 'more than 10 years ago' and so on, with a score of 5/5 for a test 'less than a year ago'. Changes in screening behaviour for the whole group are shown for 'ever' v. 'never' and for

Table 1. Knowledge scores before and after health education for all women who completed Q1 and Q2 ( $N=777)$

\begin{tabular}{|c|c|c|c|c|c|c|}
\hline \multirow[b]{2}{*}{ Score } & \multicolumn{2}{|c|}{ Knowledge of symptoms } & \multicolumn{2}{|c|}{ Knowledge of screening } & \multicolumn{2}{|c|}{ Knowledge of vaccination } \\
\hline & $\begin{array}{c}\text { Before health } \\
\text { education }\end{array}$ & $\begin{array}{l}\text { After health } \\
\text { education }\end{array}$ & $\begin{array}{c}\text { Before health } \\
\text { education }\end{array}$ & $\begin{array}{l}\text { After health } \\
\text { education }\end{array}$ & $\begin{array}{c}\text { Before health } \\
\text { education }\end{array}$ & $\begin{array}{c}\text { After health } \\
\text { education }\end{array}$ \\
\hline 0 & 239 & 115 & 539 & 288 & 43 & 34 \\
\hline 1 & 215 & 199 & 150 & 254 & 45 & 16 \\
\hline 2 & 135 & 152 & 67 & 135 & 552 & 99 \\
\hline 3 & 109 & 163 & 18 & 61 & 32 & 76 \\
\hline 4 & 68 & 131 & 2 & 39 & 17 & 15 \\
\hline 5 & 11 & 17 & 1 & 0 & 88 & 537 \\
\hline
\end{tabular}

Table 2. Changes in knowledge scores

\begin{tabular}{|c|c|c|c|}
\hline Questionnaire 1 & \multicolumn{2}{|c|}{ Questionnaire 2} & Questionnaire 1 totals \\
\hline \multicolumn{4}{|c|}{ A. Changes in knowledge scores about cervical cancer and its symptoms $(p<0.005)$} \\
\hline & Inadequate knowledge & Adequate knowledge & \\
\hline & Score 0 & Score 1 - 5 & \\
\hline Inadequate knowledge & 71 & 168 & 239 \\
\hline Score 0 & & & \\
\hline Adequate knowledge & 44 & 494 & 538 \\
\hline Score $1-5$ & & & \\
\hline Questionnaire 2 totals & 115 & 662 & 777 \\
\hline \multicolumn{4}{|c|}{ B. Changes in knowledge scores about protection by screening $(p<0.005)$} \\
\hline & Inadequate knowledge & Adequate knowledge & \\
\hline & Score 0 & Score 1 - 5 & \\
\hline Inadequate knowledge & 235 & 304 & 539 \\
\hline Score 0 & & & \\
\hline Adequate knowledge & 53 & 185 & 238 \\
\hline Score $1-5$ & & & \\
\hline Questionnaire 2 totals & 288 & 489 & 777 \\
\hline \multicolumn{4}{|c|}{ C. Changes in knowledge scores about cervical cancer protection by vaccination $(p<0.05)$} \\
\hline & Inadequate knowledge & Adequate knowledge & \\
\hline & Score 0 - 2 & Score 3 - 5 & \\
\hline Inadequate knowledge & 133 & 507 & 640 \\
\hline Score 0 - 2 & & & \\
\hline Adequate knowledge & 16 & 121 & 137 \\
\hline Score $3-5$ & & & \\
\hline Questionnaire 2 totals & 149 & 628 & 777 \\
\hline
\end{tabular}


Table 3. Self-reported screening behaviour

\begin{tabular}{|c|c|c|c|}
\hline Questionnaire 1 & \multicolumn{2}{|c|}{ Questionnaire 2} & Questionnaire 1 totals \\
\hline \multicolumn{4}{|c|}{ A. Self-reported screening behaviour: never $v$. any cervical screening history $(p<0.005)$} \\
\hline & $\begin{array}{c}\text { Never screened } \\
\text { Score } 0\end{array}$ & $\begin{array}{c}\text { Ever screened } \\
\text { Score } 1 \text { - } 5\end{array}$ & \\
\hline $\begin{array}{l}\text { Never screened } \\
\text { Score } 0\end{array}$ & 194 & 144 & 338 \\
\hline $\begin{array}{l}\text { Ever screened } \\
\text { Score } 1 \text { - } 5\end{array}$ & 33 & 358 & 391 \\
\hline Questionnaire 2 totals & 227 & 502 & 729 \\
\hline \multicolumn{4}{|c|}{ B. Screening before v. during the past year $(p<0.005)$} \\
\hline & $\begin{array}{c}\text { Screened }>1 \text { year ago } \\
\text { Score } 0-4\end{array}$ & $\begin{array}{c}\text { Screened } \leq 1 \text { year ago } \\
\text { Score } 5\end{array}$ & \\
\hline $\begin{array}{l}\text { Screened }>1 \text { year ago } \\
\text { Score } 0-4\end{array}$ & 421 & 134 & 555 \\
\hline $\begin{array}{l}\text { Screened } \leq 1 \text { year ago } \\
\text { Score } 5\end{array}$ & 44 & 130 & 174 \\
\hline Questionnaire 2 totals & 465 & 264 & 729 \\
\hline
\end{tabular}

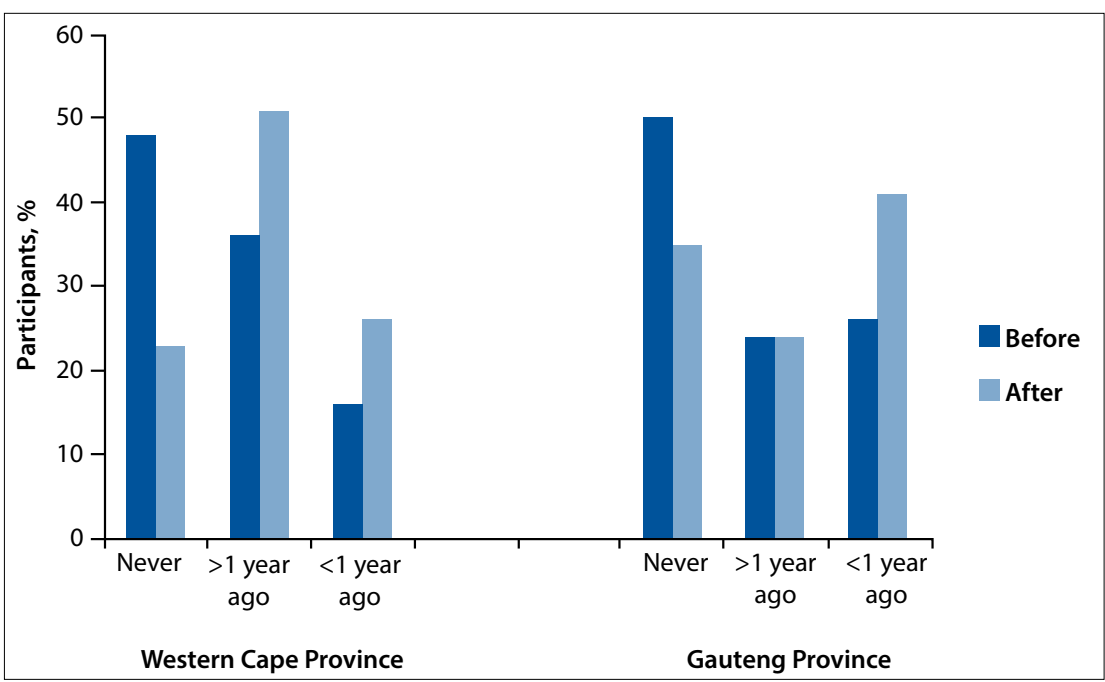

Fig. 1. Self-reported screening behaviour before and after health intervention for the two sites.

'less than 1 year ago' v. 'more than a year ago' in Table 3. Using both cut-offs, a significant improvement was demonstrated over the study period $(p<0.005)$.

\section{Screening behaviour in the two sites}

The initial self-reported screening behaviour for the two provincial sites showed no significant differences. Changes in screening behaviour reflected significantly more recent screening after the health education at both sites. In GP, where self-screening was also offered, changes in screening behaviour were more favourable (Fig. 1).

The improvement in screening behaviour as reported by women themselves underestimated the impact of this health inter- vention in the GP site, when compared with the self-screening data. It was confirmed that 253 of the 558 women (45.3\%) who completed Q1 handed in a self-collected screening test, while only 51 women moved to the 'less than 1 year ago' category in Q2.

Among participants in the WC, the number of women reporting 'never' screening decreased and those who reported 'more than 1 year ago' increased, suggesting that the health information motivated women to improve screening behaviour. However, a search through the data system of the National Health Laboratory Service could not confirm recent screening at this laboratory (which services all public health care facilities) in more than a very limited number of participants.

\section{Discussion}

This study showed that simple health education during a vaccine implementation project can have a measurable effect on the knowledge of mothers of primary schoolchildren and that significant improvements in knowledge about symptoms, screening and vaccination could be demonstrated. Importantly, we also demonstrated that increased knowledge scores can be linked to improved screening behaviour when opportunities for screening were easy to access. ${ }^{[11]}$ Lack of knowledge about disease detection and prevention has often been linked to high prevalence and late diagnosis of cervical cancer, but evidence about interventions to address this problem effectively is limited. ${ }^{[4]}$ Consistent with previous reports, the present study confirmed that many SA women at risk for cervical cancer lack even the most basic knowledge about the disease and how they can protect themselves. ${ }^{[5,6]}$

These results support HPV vaccination campaigns as a potential platform to supply health information about cervical cancer that can influence screening decisions. Mothers and other female guardians of primary schoolchildren are at the ideal age for cervical screening and are socially and economically critically important. During this study the educational intervention consisted of a combination of an oral presentation and written material, which will probably not be possible on a nationwide scale. Although alternative educational initiatives should preferably be tested before wide implementation, a minimum of written 
educational material should be offered addressing the risk of nonvaccinated women and offering alternative cancer prevention via screening. ${ }^{[8]}$

Answers to questions that tested attitude toward vaccination in general were overwhelmingly positive, with parents showing healthseeking behaviour where their children were involved. The positive attitude towards vaccines may also reflect previous good experiences with the childhood vaccine programme. We trust that these positive results will contribute to widespread acceptance and successful introduction of the new and essential HPV vaccines in SA and similar developing countries.

Women offered on-site self-screening had a larger improvement in self-reported screening behaviour than those invited to use existing facilities. ${ }^{[1]}$ The uptake of the test was calculated and the results support this finding. Observed uptake of self-screening was higher than what was reported by the respondents, cautioning that women did not understand that this test was indeed a new type of cancer screening test. Improvements in self-reported screening data among participants who were invited to screen at existing clinics were not supported by other data sources available to us and should be interpreted with caution.

\section{Study limitations}

Limitations of our study include the inherent limitations of administered questionnaires, difficulties in assessing knowledge and attitudes accurately using a questionnaire, and the potential inaccuracy of self-reported data on the use of health services. Inconsistent data on screening behaviour between the two questionnaires and between women's reports and other data sources demonstrate this inaccuracy. Women may not recall the time since their last screening test accurately, and the results of these questions may also be influenced by social desirability bias.

\section{Conclusion}

The results of this questionnaire study demonstrate that knowledge about cervical cancer among SA women at risk for the disease is lacking, but can be improved significantly by simple educational interventions. School-based HPV vaccination programmes provide an opportunity for successful education that can include information about vaccination and screening.

Additionally, this project showed that HPV vaccine programmes can be used to improve cervical cancer screening coverage. Selfcollected molecular tests that were provided at the information events achieved higher uptake than a reminder to use the existing clinic-based service, and all women received results using schoolbased logistics.

It is hoped that the overwhelmingly positive attitude towards vaccination found during this study predicts a high uptake of preadolescent HPV vaccine outside the research setting.

Acknowledgements. We gratefully acknowledge the assistance of the following groups and persons that enabled the successful completion of this project.
The VACCS study was supported financially by the Cancer Research Initiative of South Africa, a national collaborative research programme supported by the South African Medical Research Council and the Cancer Association of South Africa.

Vaccine manufacturing companies (GlaxoSmithKline Biologicals SA and Merck) approved the protocol and supported this investigator-initiated study by generously donating all vaccines used in this project.

The screening programme as well as treatment of screen-positive women was funded by the 1st for Women Foundation.

We wish to acknowledge the efforts and inputs of Prof. Gerhard Lindeque, who provided valuable advice; Ms Bertha Grond, who managed the finances; study co-ordinator Ms Riekie Burden and her team of registered nurses, who handled all study and vaccine processes seamlessly; Dr Karin Richter, who managed the laboratory screening tests; consultants and registrars of the Department of Obstetrics and Gynaecology, University of Pretoria, who presented lectures at the information events; and the undergraduate medical students who administered the questionnaires and gave us valuable feedback.

The funders were given the opportunity to review a preliminary version of this manuscript for factual accuracy, but the authors are solely responsible for final content and interpretation.

\section{References}

1. Jemal A, Bray F, Center MM, Ferlay J, Ward E, Forman D. Global cancer statistics. CA Cancer J Clin 2011;61(2):69-90. [http://dx.doi.org/10.3322/caac.20107]

2. Ferlay J, Soerjomataram I, Ervik M, et al. GLOBOCAN 2012 vl.0, Cancer Incidence and Mortality Worldwide: IARC CancerBase No. 11. Lyon, France: International Agency for Research on Cancer 2013. http://globocan.iarc.fr (accessed 10 March 2014).

3. Bruni L, Barrionuevo-Rosas L, Albero G, et al. ICO Information Centre on HPV and Cancer (HPV Information Centre). Human Papillomavirus and Related Diseases in the World. Summary Report 2015-04-08. http://www.hpvcentre.net/statistics/reports/XWX.pdf (accessed 27 March 2015).

4. Francis SA, Nelson J, Liverpool J, et al. Examining attitudes and knowledge about HPV and cervical Francis SA, Nelson J, Liverpool J, et al. Examining attitudes and knowledge about HPV and cervical
cancer risk among female clinic attendees in Johannesburg, South Africa. Vaccine 2010;28(50):8026cancer risk among female clinic attendees in Johannes

5. Van Schalkwyk SL, Maree JE, Wright SC. Cervical cancer: the route from signs and symptoms to treatment in South Africa. Reprod Health Matters 2008;16(32):9-17. [http://dx.doi.org/10.1016/S09688080(08)32399-4]

6. Hoque M. Awareness of cervical cancer, Papanicolau's smear and its utilization among female, final year undergraduates in Durban, South Africa. J Cancer Res Ther 2013;9(1):25-28. [http://dx.doi. org/10.4103/0973-1482.110350

7. Francis SA, Battle-Fisher M, Liverpool J, et al. A qualitative analysis of South African women's knowledge, attitudes, and beliefs about HPV and cervical cancer prevention, vaccine awareness and acceptance, and maternal-child communication about sexual health. Vaccine 2011:29(47):8760-8765. [http://dx. doi.org/10.1016/j. vaccine.2011.07.116]

8. MacPhail C, Venables E, Rees $\mathrm{H}$, et al. Using HPV vaccination for promotion of an adolescent package of care: Opportunity and perspectives. BMC Public Health 2013;13:493. [http://dx.doi. rg/10.1186/1471-2458-13-493]

9. Ropero-Álvarez AM, Kurtis HJ, Danovaro-Holliday MC, et al. Vaccination week in the Americas: An opportunity to integrate other health services with immunization. J Infect Dis 2012;205(suppl ):S120-S125. [http://dx.doi.org/10.1093/infdis/jir773]

10. Kharbanda EO, Stockwell MS, Fox H, et al. The role of human papillomavirus vaccination in promoting delivery of other preventive and medical services. Acad Pediatr 2011;11(4):326-332. [http:// dx.doi.org/10.1016/j.acap.2010.12.013]

11. Snyman LC, Dreyer G, Botha MH, van der Merwe FH, Becker PJ. The Vaccine and Cervical Cancer Screen (VACCS) project: Linking cervical cancer screening to HPV vaccination in the South West District of Tshwane, Gauteng, South Africa. S Afr Med J 2015;105(2):115-120. [http://dx.doi. org/10.7196/SAMJ.8418

12. Botha MH, van der Merwe FH, Snyman LC, Dreyer G. The Vaccine and Cervical Cancer Screen (VACCS) project: Acceptance of human papillomavirus vaccination in a school based program in two provinces of South Africa. S Afr Med J 2015;105(1):40-43. [http://dx doi.org/10.7196/SAMJ.8419]

13. Van der Mere $\mathrm{FH}$, Bo

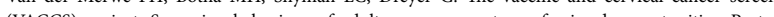
(VACCS) project: Screening behaviour of adult women - a story of missed opportunities. Poster November 2014, Melbourne, Australia.

Accepted 28 September 2015 


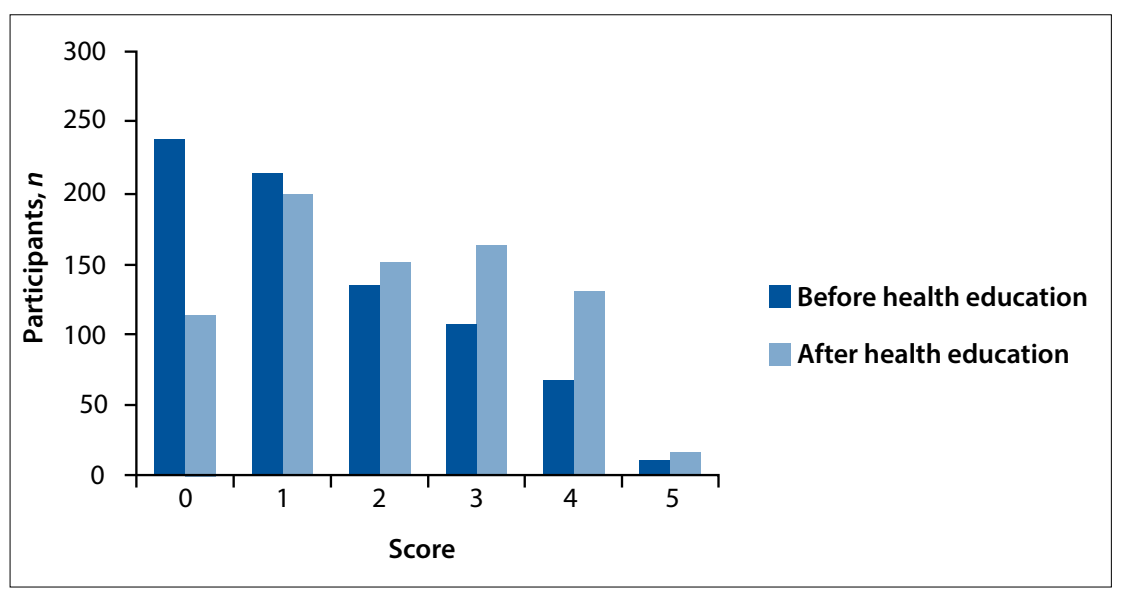

Diagram 1. Knowledge of cervical cancer symptoms.

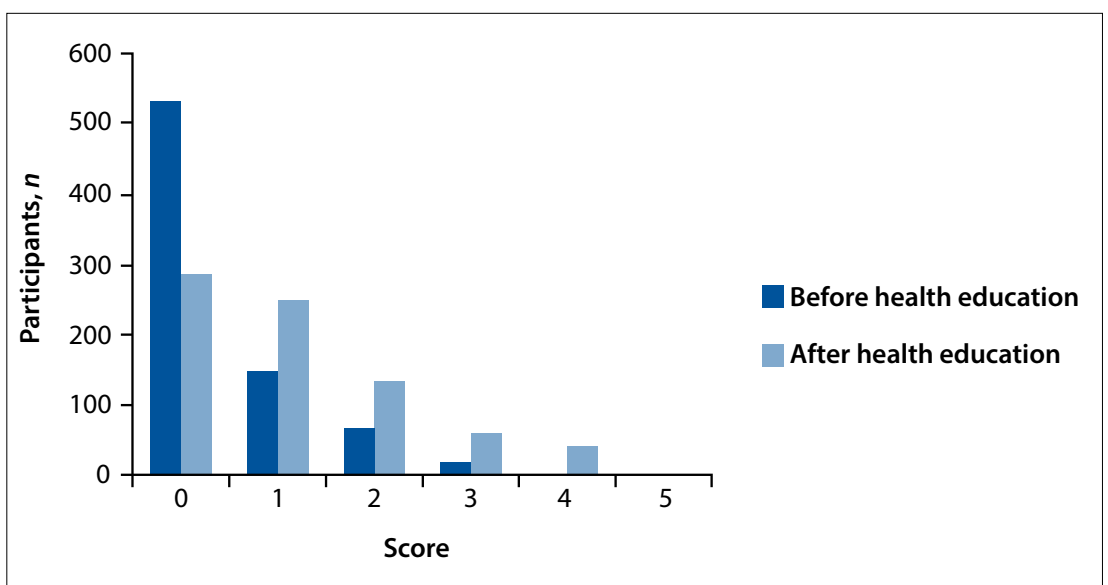

Diagram 2. Knowledge of cervical cancer screening.

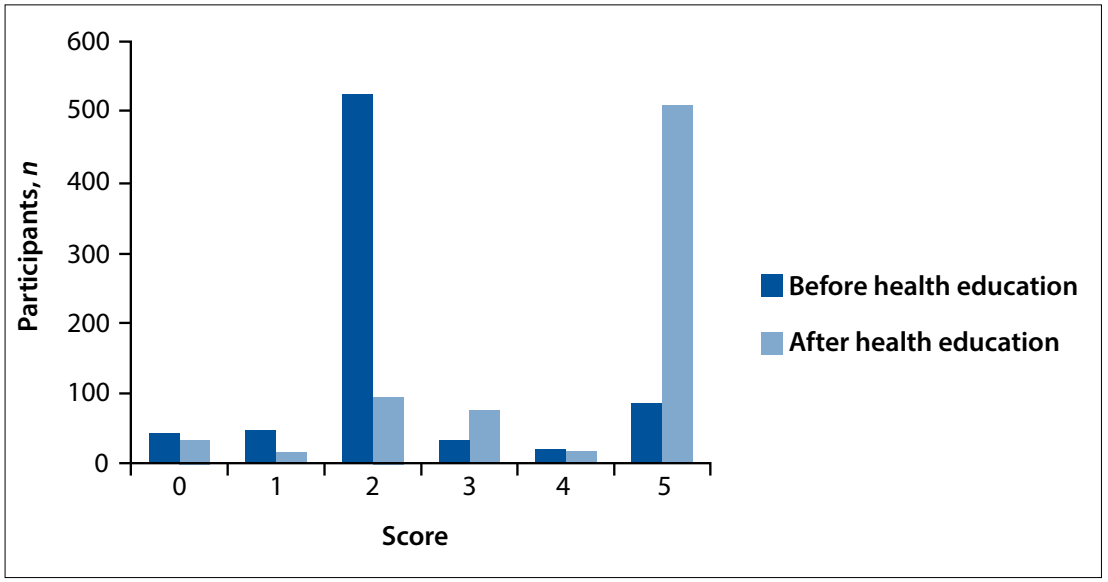

Diagram 3. Knowledge of cervical cancer vaccination. 
Appendix 1. Calculation of knowledge scores from responses in questionnaires 1 and 2

Score calculation: 'Knowledge about cervical cancer symptoms'

Points awarded

Question

$301 \& 601$. Can you explain what Do not know

0

you understand about cervica

cancer - that is cancer of the

Any correct or nearly correct answer 1

mouth of the womb?
$303 \& 603$. What changes in your body would make you think that
you had cervical cancer?
Pain
1 point each
Discharge from vagina
Odour from vagina
Unusual bleeding

Score calculation: 'Knowledge about protection against cervical cancer'

\begin{tabular}{lll}
\hline Question & Response & $\begin{array}{c}\text { Points awarded } \\
\text { (maximum of 5) }\end{array}$ \\
\hline 304 \& 604. How can a & Regular pap smear & 1 point each \\
woman protect herself against & Regular examination of womb & \\
developing cervical cancer? & Not having sex & \\
& Using condoms & \\
& Vaccine/injection & \\
& Other screening tests \\
Score calculation: 'Knowledge about cervical cancer protection by vaccination'
\end{tabular}

\begin{tabular}{|c|c|c|}
\hline Question & Response & $\begin{array}{l}\text { Points awarded } \\
\text { (maximum of } 5 \text { ) }\end{array}$ \\
\hline $\begin{array}{l}501 \& 801 . \text { Have you ever heard } \\
\text { of a vaccine or injection to } \\
\text { prevent cervical cancer? }\end{array}$ & Yes & 1 \\
\hline $\begin{array}{l}502 \& 802 \text {. IF YES: Who is the } \\
\text { vaccine or injection for? }\end{array}$ & $\begin{array}{l}\text { Women/girls only } \\
\text { Men and women/girls } \\
\text { Women/girls under a certain age } \\
\text { Women/girls who have not had } \\
\text { sexual intercourse yet }\end{array}$ & 2 points each \\
\hline $\begin{array}{l}503 \& 803 \text {. Do you think a } \\
\text { vaccine to prevent cervical } \\
\text { cancer would be good to have? }\end{array}$ & Yes & 1 \\
\hline $\begin{array}{l}505 \& 805 \text {. Would you advise } \\
\text { primary school girls to have this } \\
\text { vaccine? }\end{array}$ & Yes & 1 \\
\hline
\end{tabular}


Appendix 2. Answers to open-ended question: 'What do you understand about cervical cancer?'

\begin{tabular}{|c|c|c|}
\hline Response & $\begin{array}{l}\text { Q1, question } 301 \\
(N=750) \\
n(\%)\end{array}$ & $\begin{array}{l}\text { Q2, question } 601 \\
(N=714) \\
n(\%)\end{array}$ \\
\hline Don't know/nothing & $308(41.0)$ & $112(15.7)$ \\
\hline Cancer of the mouth of the womb or cervix & $69(9.2)$ & $175(24.5)$ \\
\hline $\begin{array}{l}\text { Cancer, illness, growth, sores or bleeding of the } \\
\text { womb }\end{array}$ & $192(25.6)$ & $278(38.9)$ \\
\hline Must have Pap smears & $33(4.4)$ & $10(1.4)$ \\
\hline Cancer of private parts/affects only women & $27(3.6)$ & $53(7.4)$ \\
\hline STD/can get from unsafe sex & $31(4.1)$ & $34(4.8)$ \\
\hline $\mathrm{HPV} /$ virus & $5(0.7)$ & $12(1.7)$ \\
\hline Self, friend, family member has it & $6(0.8)$ & $2(0.3)$ \\
\hline Type of cancer & $12(1.6)$ & $3(0.4)$ \\
\hline Abnormal cells, growth, lump, mass, cyst & $9(1.2)$ & $1(0.1)$ \\
\hline Dangerous, fatal, incurable disease & $19(2.5)$ & $6(0.8)$ \\
\hline Affects vagina & $13(1.7)$ & $15(2.1)$ \\
\hline
\end{tabular}

Appendix 3. Answers to open-ended question: 'What changes in the body would make you think that you had cervical cancer?'

\begin{tabular}{lll}
\hline Response & $\begin{array}{l}\text { Q1, question } 302 \\
(\boldsymbol{N = 9 0 6 )}\end{array}$ & $\begin{array}{l}\text { Q2, question 602 } \\
(\boldsymbol{N}=777)\end{array}$ \\
\hline Pain & $\boldsymbol{n}(\%)$ & $359(46.2)$ \\
Discharge & $272(30.0)$ & $249(32.0)$ \\
Odour & $189(20.9)$ & $137(17.6)$ \\
Ulcers/sores & $92(10.1)$ & $140(18.0)$ \\
Unusual bleeding & $64(7.1)$ & $327(42.1)$ \\
There are no signs & $185(20.4)$ & $8(1.0)$ \\
Don't know & $11(1.2)$ & $90(11.6)$
\end{tabular}

Appendix 4. Answers to open-ended question: 'How can a woman protect herself against cervical cancer?'

\begin{tabular}{lll}
\hline & $\begin{array}{l}\text { Q1, question } 304 \\
(\boldsymbol{N = 9 0 6 )} \\
\boldsymbol{n}(\%)\end{array}$ & $\begin{array}{l}\text { Q2, question 604 } \\
(\boldsymbol{N}=\mathbf{7 7 7})\end{array}$ \\
\hline $\begin{array}{ll}\boldsymbol{n}(\%) \\
\text { Pap smear }\end{array}$ & $223(24.6)$ & $419(53.9)$ \\
Regular examination of womb & $74(8.2)$ & $126(16.2)$ \\
Seeing a special doctor & $38(4.2)$ & $124(16.0)$ \\
Regular visit to general practitioner & $30(3.3)$ & $43(5.5)$ \\
Not having sex & $22(2.4)$ & $18(2.3)$ \\
Using condoms & $61(6.7)$ & $113(14.5)$ \\
Vaccine/injection & $38(4.2)$ & $205(26.4)$ \\
Other screening tests & $21(2.3)$ & $28(3.6)$
\end{tabular}

